\title{
Delayed platelet engraftment in group 0 patients after autologous progenitor cell transplantation
}

\author{
Sandra Hoffmann, Lan Zhou, Yuan Gu, Robertson Davenport, and Laura Cooling
}

BACKGROUND: Fucosylated glycans, including $\mathrm{H}$ antigen, play critical roles in hematopoietic progenitor cell homing, adhesion, growth, and differentiation. $\mathrm{H}$-active antigens are strongly expressed on CD34+ progenitor cells and committed megakaryocytic progenitors and may mediate adhesion to marrow stromal fibroblasts. We examined the possible influence of donor $A B O$ type on platelet (PLT) engraftment after autologous peripheral blood progenitor cell transplant (PBPCT).

STUDY DESIGN AND METHODS: A retrospective analysis of all patients who underwent a single autologous PBPCT between 1996 and 2000 were reviewed. Neutrophil and PLT engraftment were compared by patient $\mathrm{ABO}$ type and $\mathrm{CD} 34+$ cell dose by $t$ test, chi-square test, analysis of variance, Kaplan-Meier probability, and log-rank test.

RESULTS: Engraftment data was available in 195 patients. PLT engraftment was delayed in all patients, regardless of $\mathrm{ABO}$ type, at $\mathrm{CD} 34+\mathrm{PBPC}$ doses of $2 \times 10^{6}$ to $3 \times 10^{6}$ per $\mathrm{kg}(p<0.001)$. When examined by ABO type, late PLT engraftment (PLT count $>50 \times 10^{\circ} / \mathrm{L}$ ) was significantly delayed in group $O$ patients relative to all non-group $O$ patients (32.4 days vs. 19.6 days, $p<0.001$ ). Approximately 50 percent of group $O$ patients required more than 40 days to achieve late PLT recovery $(p<0.005)$.

CONCLUSIONS: A group O phenotype may be associated with delayed PLT engraftment at lower CD34 doses.



ell-surface carbohydrates, particularly those containing fucose, play integral roles in hematopoietic cell adhesion, growth, and differentiation. ${ }^{1,2}$ Lewis X $\left(\mathrm{Le}^{\mathrm{X}}\right)$ and sialylated Lewis X (sLe ${ }^{\mathrm{X}}$; Table 1) are two blood group-related antigens that serve as ligands for selectins (L-, P-, and E-selectin) - a family of vascular addressins that mediate white blood cell (WBC) adhesion to endothelium. ${ }^{3,4}$ Among hematopoietic cells, $\mathrm{Le}^{\mathrm{X}}$ and $\mathrm{sLe}^{\mathrm{X}}$ are expressed on CD34+ progenitor cells, early lymphoid progenitors, monocytes, and granulocytes, where they facilitate homing to marrow sinusoids, lymph nodes, and sites of inflammation. ${ }^{1,3,5}$ Fucosylation also plays a central role in the Notch signaling pathway, an evolutionarily conserved system regulating cell differentiation. In hematopoiesis, Notch preserves stem cell repopulating cells, ${ }^{6,7}$ favoring lymphoid and dendritic cell differentiation while inhibiting erythroid and terminal myeloid differentiation. ${ }^{8,9}$ Loss and/or modification of several unusual O-linked fucoses present on epidermal growth factor repeats can profoundly alter Notch ligand binding and hematopoietic differentiation. ${ }^{10-12}$

There is increasing evidence that $\mathrm{H}$ - and $\mathrm{H}$-active antigens may also be developmentally important antigens in early hematopoiesis. Recently, Cao and colleagues ${ }^{13}$ reported that $\mathrm{CD} 34+$ progenitor cells are positive for Type 2 chain $\mathrm{H}$ (H-2, CD173; Table 1) and Lewis Y (Le $\mathrm{Y}^{\mathrm{r}}$; CD174), a difucosylated oligosaccharide related to $\mathrm{Le}^{\mathrm{X}}$ with blood group $\mathrm{H}$-activity. ${ }^{13}$ Parallel studies have con-

ABBREVIATIONS: ECM = extracellular matrix; LeX = Lewis X; LeY, Lewis Y; PLT = platelets; PBPCT = peripheral blood progenitor cell transplant; sLeX = sialylated Lewis X.

From the Department of Pathology, University of Michigan, Ann Arbor, Michigan.

Address reprint requests to: Laura Cooling, MD, MS, Clinical Assistant Professor, Associate Medical Director, Transfusion Medicine, Department of Pathology, University of Michigan Hospitals, 2F225 UH, Box 0054, 1500 East Medical Center Drive, Ann Arbor, MI 48109; e-mail: lcooling@med.umich.edu.

Received for publication August 20, 2004; revision received November 22, 2004, and accepted November 26, 2004.

doi: $10.1111 /$ j.1537-2995.2005.04346.x

TRANSFUSION 2005;45:885-895. 


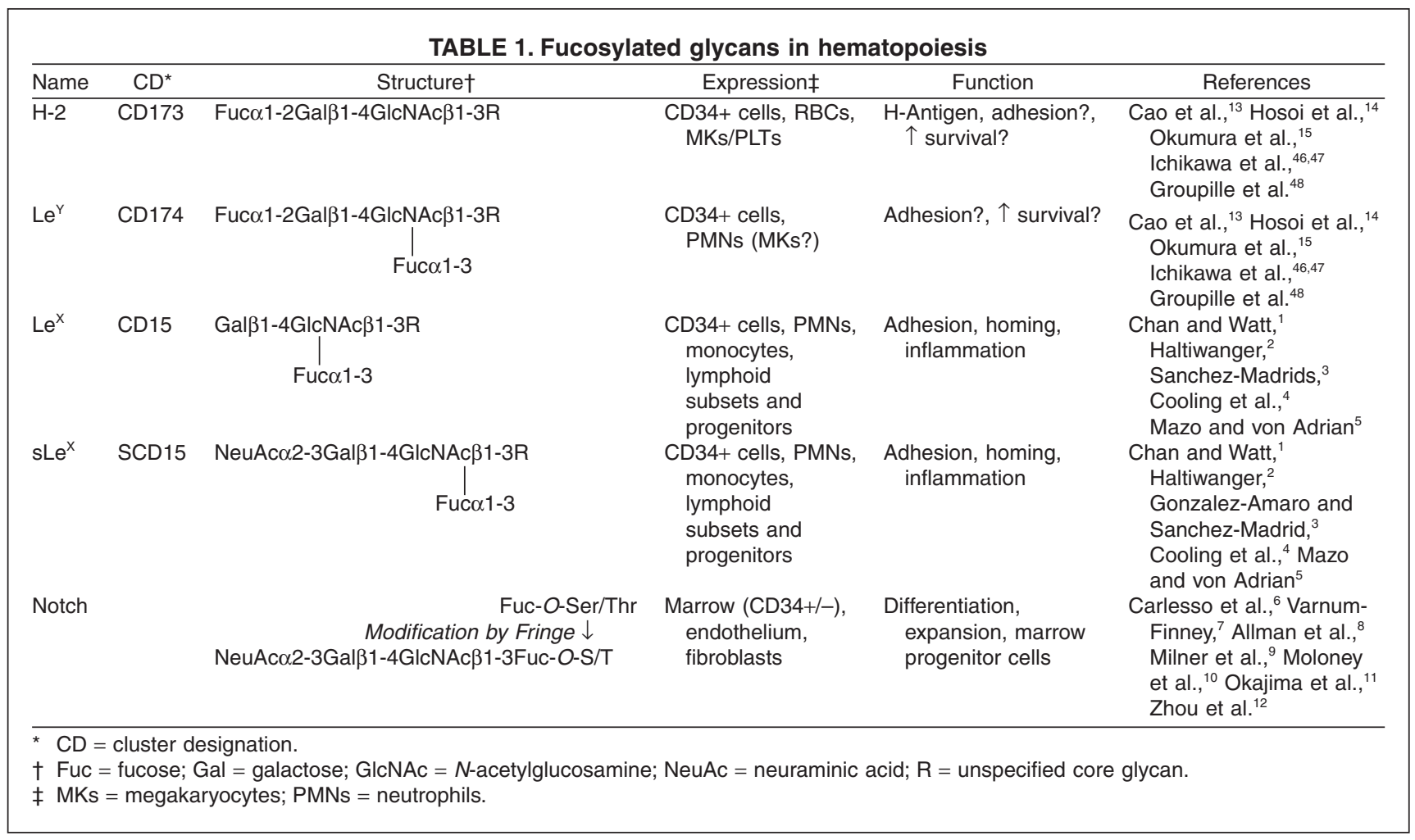

firmed the presence of FUT1, the $\alpha 1,2$-fucosyltransferase responsible for $\mathrm{H}-2$ and $\mathrm{Le}^{\mathrm{Y}}$ synthesis, in CD34+ progenitors. ${ }^{14}$ Expression of $\mathrm{H}-2, \mathrm{Le}^{\mathrm{Y}}$, and FUT1 is relatively specific for early hematopoietic progenitors and is lost with increasing lymphoid and myeloid differentiation. ${ }^{13,14}$

$\mathrm{H}$-antigen may also play a role in megakaryocytic differentiation. H-antigen is commonly expressed in megakaryoblastic leukemia, in conjunction with CD34 and glycoprotein IIb/IIIa (CD41), an early megakaryocyte marker. ${ }^{15}$ Likewise, monoclonal antibody MG-2 (MoAb MG-2), an antibody against early megakaryocytic progenitors and megakaryoblastic leukemia, appears to recognize an H-active antigen. ${ }^{15}$ In immortalized megakaryoblastic cell lines, $\mathrm{H}$ - and MG-2 antigens are progressively lost with increasing megakaryocytic maturation and proplatelet formation. ${ }^{15}$ Finally, Schmitz and coworkers $^{16}$ have reported that megakaryocyte adhesion to marrow stromal fibroblasts is fucose-dependent, inhibited by both $\mathrm{H}$-active lectins (Ulex europeaus lectin-1) and soluble $\mathrm{H}$-antigen. A role for $\mathrm{H}$-antigen in mediating stromal cell adhesion could have important implications for ex vivo megakaryocyte expansion as well as platelet (PLT) recovery following chemotherapy and marrow transplantation. Expansion and long-term preservation of megakaryocytic progenitors requires direct contact and adherence to stromal fibroblasts and extracellular matrix proteins (ECM). ${ }^{17,18}$

Based on these findings, we hypothesized that $\mathrm{ABO}$ type may influence the rate of PLT engraftment after che- motherapy or autologous progenitor cell transplant. Specifically, we hypothesized that group $\mathrm{O}$ patients may have accelerated PLT recovery owing to prolonged expression of H-antigen on developing megakaryocytes. To examine this question, we retrospectively reviewed WBC and PLT engraftment times in patients undergoing an autologous peripheral blood progenitor cell transplant (PBPCT).

\section{MATERIALS AND METHODS}

\section{Patients}

The study was confined to a retrospective analysis of all patients who underwent autologous peripheral blood progenitor cell (PBPC) collection at our institution between 1996 and 2000. Inclusion criteria were an age of more than 18 years at the time of PBPC collection, followed by a single autologous PBPCT at our institution. Of 263 patients who underwent PBPC collection, 195 (74\%) were included for analysis (Table 2). Sixty-eight patients were excluded because of a prior transplant or back-toback double transplant $(n=16)$, transplant with PBPCs and marrow $(n=8)$, transplant at an outside facility $(n=2)$, postcollection CD34+ selection $(n=1)$, no transplant $(n=37)$, and death before engraftment $(n=7)$. All patients were enrolled in clinical trials approved by the human research institutional review board of the University of Michigan. Informed consent was obtained from all patients before leukapheresis and treatment. 


\begin{tabular}{|c|c|c|}
\hline Characteristic & Number & Percentage \\
\hline All patients & 195 & 100 \\
\hline \multicolumn{3}{|l|}{ Diagnosis } \\
\hline Hodgkin's lymphoma & 53 & 27.2 \\
\hline Non-Hodgkin's lymphoma & 64 & 32.8 \\
\hline Multiple myeloma & 63 & 32.3 \\
\hline Breast cancer & 13 & 6.7 \\
\hline Ewing's sarcoma & 1 & 0.5 \\
\hline Testicular cancer & 1 & 0.5 \\
\hline \multicolumn{3}{|l|}{ Sex } \\
\hline Male & 116 & 59.5 \\
\hline Female & 79 & 40.5 \\
\hline Mean $( \pm$ SD) age (years) & $\begin{array}{c}46.9 \pm 15.5 \\
\text { (range, 19-71) }\end{array}$ & 100 \\
\hline \multicolumn{3}{|l|}{ ABO type } \\
\hline Group A & 85 & 43.6 \\
\hline Group O & 74 & 38.5 \\
\hline Group B & 24 & 12.3 \\
\hline Group AB & 12 & 6.0 \\
\hline \multicolumn{3}{|c|}{ CD34 cell dose ( $\times 10^{6} / \mathrm{kg}$ of body weight) } \\
\hline Low $(2$ to $<3)$ & 76 & 39 \\
\hline Intermediate (3 to 5 ) & 40 & 20.5 \\
\hline High $(\geq 5)$ & 79 & 40.5 \\
\hline \multicolumn{3}{|l|}{ Engraftment data } \\
\hline WBC & 195 & 100 \\
\hline PLT & 170 & 87 \\
\hline Early $\left(>20 \times 10^{9} / \mathrm{L}\right)$ & 170 & 87 \\
\hline Late $\left(>50 \times 10^{9} / \mathrm{L}\right)$ & 155 & 79.5 \\
\hline
\end{tabular}

lines. CD34+ yields and cell viability were determined by a whole-blood lysis technique and flow cytometry as recommended by the International Society of Hematology and Graft Engineering (ISHAGE). ${ }^{19}$ Samples $(30 \mu \mathrm{L})$ were stained with a phycoerythrin-labeled monoclonal anti-CD34 (MoAb 581), fluorescein-labeled anti-CD14 (MoAb MY4), energy-coupled dye-labeled CD45 (MoAb J.33), and 7-aminoactinomycinD (Molecular Probes, Eugene, OR) for 10 minutes at room temperature. Analysis was subsequently performed on a flow cytometer (Coulter EPICS XL-MCL, Beckman Coulter, Miami, FL) with ISHAGE acquisition layouts. Briefly, mononuclear cells (MNCs) were initially gated on CD45 fluorescence, side and forward scatter. Nonviable cells were excluded based on 7-aminoactinomycin-D fluorescence. The percentage of CD34+ cells was determined in the CD45+, CD14- fraction after counting 50,000 events. To calculate the total CD34+ cell yield, the percentage of

\section{PBPC mobilization and collection}

PBPCs were mobilized in all patients by a combination of disease-oriented chemotherapy and granulocyte-colonystimulating factor (G-CSF; $10 \mu \mathrm{g}$ per $\mathrm{kg}$ per day). Six patients received escalating doses of G-CSF $(12-16 \mu \mathrm{g} / \mathrm{kg} /$ day) owing to poor PBPC mobilization and collection. One patient failed to collect and was remobilized with a combination of granulocyte-macrophage-colony-stimulating factor (GM-CSF; $500 \mu \mathrm{g} /$ day) and G-CSF $(10 \mu \mathrm{g} / \mathrm{kg} /$ day). PBPC collection was initiated when the peripheral WBC recovery exceeded $2 \times 10^{9}$ per $\mathrm{L}$ after chemotherapy. PBPCs were collected by processing two blood volumes by standard continuous-flow leukapheresis on an apheresis machine (COBE Spectra, COBE BCT Inc., Lakewood, CO). Leukocytopheresis was performed daily until a minimum final yield of $2 \times 10^{6} \mathrm{CD} 34+$ cells per $\mathrm{kg}$ of body weight were collected. Cells were volume-adjusted to a final concentration of less than $4 \times 10^{8} \mathrm{WBCs}$ per $\mathrm{mL}$ in 10 percent dimethyl sulfoxide, frozen in a controlled-rate freezer $\left(-1^{\circ} \mathrm{C} / \mathrm{min}\right.$ to $\left.-90^{\circ} \mathrm{C}\right)$, and stored in the liquid phase of liquid nitrogen.

\section{Product analysis}

An aliquot of each leukocytopheresis collection was subjected to a complete blood count with WBC differential. Hematopoietic colony assays were not routinely performed per our institution's transplant program guide-
CD34+ cells was multiplied by the total number of MNCs collected. All MoAbs used were purchased from Immunotech (Miami, FL).

\section{Definitions of engraftment and CD34+ cell dose}

Times for WBC and PLT engraftment were calculated from the day of PBPC infusion (Day 0). Neutrophil or WBC engraftment was defined as the first of three consecutive days to achieve a sustained absolute neutrophil count of at least $0.5 \times 10^{9} \mathrm{WBCs}$ per L. Early PLT engraftment was defined as the first day to achieve a sustained PLT count of greater than $20 \times 10^{9}$ per L $\left(20 \times 10^{9} / \mathrm{L}\right)$ in the absence of PLT transfusion support for at least 72 hours. Late PLT engraftment was defined as the first day to achieve a sustained, independent PLT count of greater than $50 \times 10^{9}$ per $\mathrm{L}$ in the absence of transfusion support. ${ }^{20,21}$

Because engraftment times are dependent on the number of CD34+ cells infused, ${ }^{20-22}$ we also classified patients as receiving a high, intermediate, and low PBPCT dose, based on the total number of CD34+ PBPCs infused at transplant. High dose was considered a weight-adjusted CD34 dose of at least $5 \times 10^{6} \mathrm{CD} 34+$ cells per $\mathrm{kg}$ body weight. Previous studies have reported that $5 \times 10^{6} \mathrm{CD} 34$ per $\mathrm{kg}$ of body weight is the threshold dose predictive for rapid PLT engraftment. ${ }^{20-24}$ Intermediate and low doses were arbitrarily established at a CD34+ cell dose of $3 \times 10^{6}$ to $5 \times 10^{6} \mathrm{CD} 34+$ cells per $\mathrm{kg}$ of body weight and $2 \times 10^{6}$ to $3 \times 10^{6} \mathrm{CD} 34+$ cells per $\mathrm{kg}$ of body weight, respectively. All 
patients analyzed received at least $2 \times 10^{6} \mathrm{CD} 34+$ cells per $\mathrm{kg}$ of body weight in accordance with our institution's guidelines.

\section{Transfusion support}

Patients were transfused with irradiated, leukoreduced red blood cells (RBCs) and whole blood-derived pooled PLT concentrates (5 units/dose) to maintain a minimum hemoglobin level of $8.0 \mathrm{~g}$ per dL and a PLT count of greater than $10 \times 10^{9}$ per $\mathrm{dL}$ according to clinical guidelines and underlying medical condition. Patients were rarely transfused with single-donor apheresis PLTs $(<1 \%$ total). Transfusion support was determined by the total number of RBCs and whole blood-derived PLT equivalents transfused during their admission for PBPCT. Singledonor apheresis PLTs, when given, were considered equivalent to seven whole blood-derived PLT concentrates.

Records were also reviewed in 54 patients transplanted at low CD34 doses for evidence of PLT refractoriness, based on an initial request for either single-donor apheresis PLTs or cross-matched or HLA-matched PLTs. No patient reviewed had a request for special PLT products. Two patients received a single unit of apheresis PLTs based on available inventory.

\section{Statistical analysis}

WBC and PLT engraftment times were analyzed and compared relative to $\mathrm{CD} 34+$ cell dose and patient $\mathrm{ABO}$ type and expressed as the mean \pm standard deviation except as indicated. Mean engraftment rates were compared by a two-tailed $t$ test. The probability of early and late PLT engraftment were calculated with the method of Kaplan and Meier $^{25}$ and compared by the logrank test. In patients transplanted at low CD34+ cell doses, categorical variables were assessed by a chi-square test, a t test, and a multivariate analysis of variance. A result was considered significant at a $\mathrm{p}$ value of less than 0.05. Because of a limited number of group $\mathrm{AB}$ and $\mathrm{B}$ patients, statistical comparisons were typically limited to group $\mathrm{O}$, group $\mathrm{A}$, and all non-group $\mathrm{O}$ patients (groups A, B, and AB). Graphics and statistical analysis were performed with computer software (Kaleidograph, Synergy Software, Reading, PA; SPSS software, SPSS, Chicago, IL).

\section{RESULTS}

\section{Patients}

A total of 195 patients, who underwent a single autologous PBPCT, were available for analysis (Table 2). More than 90 percent of patients received transplants for an underlying hematologic malignancy. Overall, there was a slight predominance in men and the group A phenotype in our study cohort. There was a broad range in the number of CD34+ PBPCs collected and infused (Table 2; Fig. 1). A comparison of patients in the three CD34+ dose categories found no significant differences by sex, ABO type, or underlying diagnosis (data not shown).

Of our 195 patients, WBC engraftment data were available in 100 percent of patients. Although all patients had achieved WBC engraftment at the time of discharge, data regarding PLT engraftment were only available in 87 percent of patients; the remaining 13 percent $(n=25)$ were still PLT transfusion-dependent at discharge. Because these latter patients were followed by their local physicians after discharge, it was not possible to document when early and late PLT engraftment occurred. Despite the latter, full PLT engraftment was documented at 100 days after transplant in most of these patients, with 17 of 25 (68\%) patients having PLT counts of greater than $100 \times 10^{9}$ per L. Poor engraftment (PLT count $\left.<50 \times 10^{9} / \mathrm{L}\right)$ and relapse $(\mathrm{n}=3)$ were noted in 6 of 25 patients.
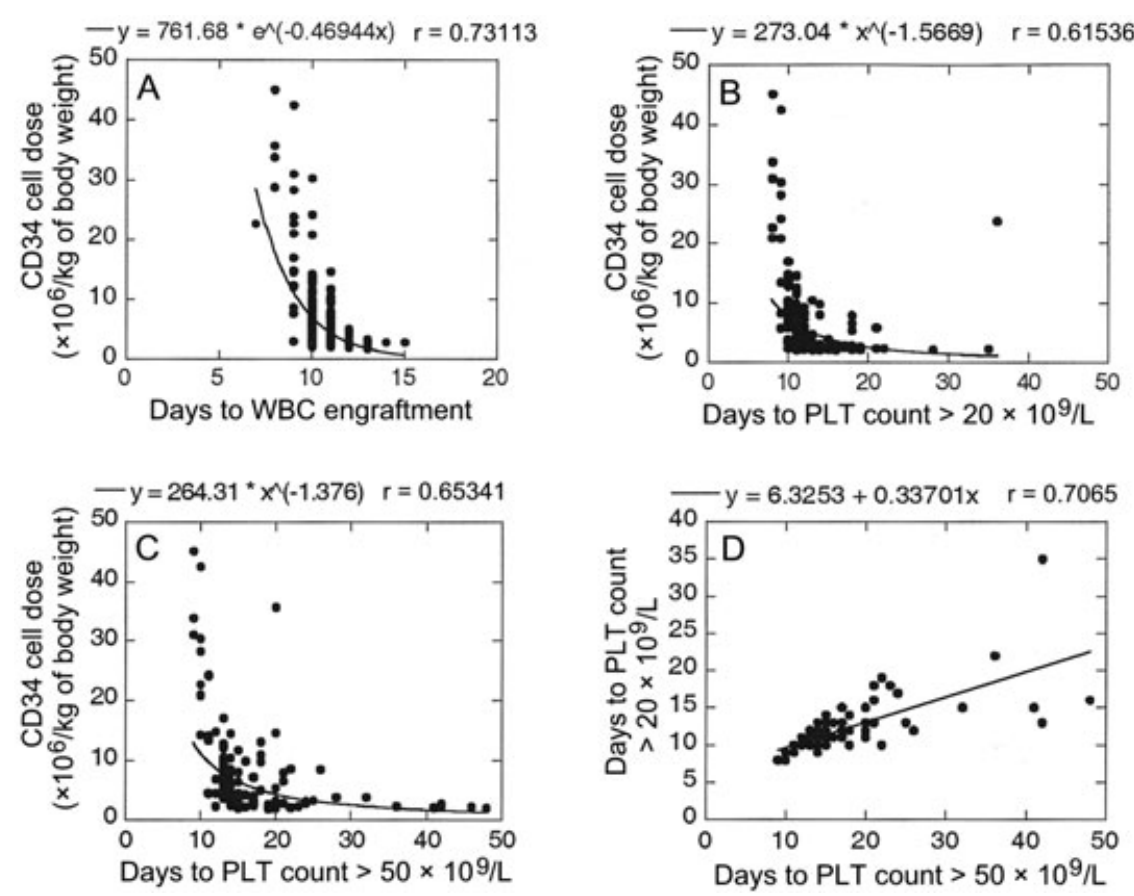

Fig. 1. Correlation between CD34+ PBPC dose and engraftment times for WBC (A) and early $\left(\mathrm{B},>20 \times 10^{9} \mathrm{~L}\right)$ and late PLT engraftment $\left(\mathrm{C},>50 \times 10^{9} / \mathrm{L}\right)$. A correlation between the time to early and late PLT engraftment was also observed (D). 


\begin{tabular}{|c|c|c|c|c|c|c|c|c|}
\hline \multirow[b]{2}{*}{ ABO type } & \multirow{2}{*}{$\begin{array}{l}\text { Number of } \\
\text { patients }\end{array}$} & \multirow{2}{*}{$\begin{array}{r}\text { CD34 cell } \\
\text { dose }\left(\times 10^{6} / \mathrm{kg}\right)\end{array}$} & \multicolumn{3}{|c|}{ Engraftment in days* } & \multicolumn{2}{|c|}{$<3$ vs. $>5 \dagger$} & \multirow{2}{*}{$\begin{array}{l}\text { vs. }>3 \| \\
\text { P value§ }\end{array}$} \\
\hline & & & Low $(<3)$ & Intermediate & High $(>5)$ & $\overline{\Delta \dagger \S}$ & $P$ valuet§ & \\
\hline \multicolumn{9}{|c|}{ WBC engraftment } \\
\hline All patients & 195 & & $11.6 \pm 1.0$ & $10.9 \pm 0.7$ & $9.9 \pm 0.9$ & 1.7 & NS & NS \\
\hline Non-group O & 121 & & $11.5 \pm 0.9$ & $10.9 \pm 0.8$ & $9.9 \pm 1.0$ & 1.6 & NS & NS \\
\hline Group A & 85 & & $11.5 \pm 1.0$ & $10.9 \pm 0.7$ & $9.8 \pm 0.9$ & 1.7 & NS & NS \\
\hline Group B & 24 & & $11.5 \pm 0.8$ & $10.7 \pm 0.6$ & $9.7 \pm 1.4$ & 1.8 & NS & NS \\
\hline Group O & 74 & & $11.9 \pm 1.1$ & $11.0 \pm 0.7$ & $10.1 \pm 0.7$ & 1.8 & NS & NS \\
\hline \multicolumn{9}{|c|}{ PLT engraftment (early, $>20 \times 10^{9} / \mathrm{L}$ ) } \\
\hline All patients & 132 & & $15.2 \pm 4.6$ & $11.8 \pm 1.3$ & $10.9 \pm 2.4$ & 4.3 & $<0.01$ & $<0.001$ \\
\hline Non-group O & 87 & & $14.6 \pm 4.2$ & $11.9 \pm 1.3$ & $10.8 \pm 2.1$ & 3.8 & $<0.01$ & $<0.02$ \\
\hline Group A & 67 & & $14.5 \pm 4.3$ & $11.8 \pm 1.5$ & $10.6 \pm 1.5$ & 3.9 & $<0.01$ & $<0.02$ \\
\hline Group B & 16 & & $14.3 \pm 2.5$ & $12.5 \pm 0.5$ & $11.0 \pm 4.4$ & 3.3 & $<0.01$ & NS \\
\hline Group O & 45 & & $16.0 \pm 2.6$ & $11.6 \pm 1.1$ & $11.2 \pm 3.0$ & 4.8 & $<0.01$ & $<0.005$ \\
\hline \multicolumn{9}{|c|}{ PLT engraftment (late, $>50 \times 10^{9} / \mathrm{L}$ ) } \\
\hline All patients & 103 & & $23 \pm 10.5$ & $16.9 \pm 5.6$ & $14.1 \pm 3.8$ & 8.9 & $<0.001$ & $<0.003$ \\
\hline Non-group O & 66 & & $19.6 \pm 7.9$ & $17.1 \pm 6.4$ & $13.7 \pm 3.5$ & 5.9 & $<0.001$ & $<0.02$ \\
\hline Group A & 48 & & $18.5 \pm 6.4$ & $16.1 \pm 6.5$ & $13.7 \pm 3.4$ & 4.8 & $<0.001$ & $<0.02$ \\
\hline Group B & 9 & & $20.5 \pm 2.2$ & & $13.8 \pm 4.0$ & 6.7 & $<0.001$ & NS \\
\hline Group O & 37 & & $32.4 \pm 13.3$ & $16.8 \pm 4.8$ & $14.7 \pm 4.2$ & 17.7 & $<0.001$ & $<0.01$ \\
\hline $\begin{array}{l}\text { * Mean } \pm \text { SD. } \\
\dagger \text { Comparison b } \\
\text { † Difference in } \\
\S \text { T test; NS = n } \\
\text { ॥ Comparison b }\end{array}$ & $\begin{array}{l}10^{6} \text { per } \\
10^{6} / \mathrm{kg}\end{array}$ & w dose) and & $5 \times 10^{6}$ per & $\begin{array}{l}\text { (high dose } \\
\text { igh dose). }\end{array}$ & & & & \\
\hline
\end{tabular}

\section{WBC engraftment}

Most patients achieved an absolute neutrophil count of greater than $0.5 \times 10^{9}$ per L within 10 to 11 days after infusion (mean $\pm \mathrm{SD}, 10.8 \pm 1.2$; range, $7-15 ; \mathrm{n}=195$ ), which is comparable to other studies. ${ }^{20-23}$ There was a mean 1- to 2-day lag in WBC engraftment at lower CD34+ cell doses, but this difference did not reach clinical significance (Table 3; Fig. 2). There was an exponential relationship between CD34+ cell dose and WBC engraftment $(r=0.73$; Fig. 1A). A comparison of WBC engraftment by ABO type found no significant differences.

\section{PLT engraftment}

The mean times necessary for early and late PLT engraftment were $12.7 \pm 4.3$ and $17.3 \pm 7.7$ days, respectively. As reported, both early and late PLT engraftment were strongly influenced by the CD34+ cell dose. ${ }^{20-22}$ On average, transplant at low CD34+ cell doses resulted in a 4- to 9-day delay in early and late PLT recovery, respectively (Table 3; Fig. 1). There was no correlation between the time to WBC engraftment and either early $(r=0.36)$ or late PLT engraftment $(r=0.38)$. A positive correlation was observed between the time to early and late PLT recovery $(r=0.70$; Fig. 1D), particularly at low CD34+ doses $(r=0.80$; data not shown $)$.

As noted by others, ${ }^{20-24}$ a CD34+ dose of greater than $5 \times 10^{6}$ per kg of body weight was highly predictive of rapid PLT recovery (Fig. 2). Early PLT engraftment was observed in these patients by Day 20 in 97 percent of patients, with the majority of patients engrafting between Day 10 (44\%) and Day $12(83 \%)$. Late PLT recovery was observed by Days 15 (76\%) and 20 (92\%). Rapid PLT recovery was also observed in most patients transplanted at a CD34+ cell dose of greater than $3 \times 10^{6}$ per $\mathrm{kg}$. At these intermediate CD34+ cell doses, early and late PLT recovery was observed by Day 12 (74\% of patients) and Day 20 (82\%), respectively. In contrast, only 22 percent of patients transplanted at a CD34+ cell dose of less than $3 \times 10^{6}$ per $\mathrm{kg}$ of body weight achieved a PLT count of greater than $20 \times 10^{9}$ per L by Day 12. Although they were excluded from our analysis, it is noteworthy that five of six patients with either poor PLT engraftment or relapse at Day +100 after transplant were transplanted at low CD34+ cell doses (2.4 \pm 0.4 ; range, 2.1-3.0).

\section{The effect of ABO on PLT engraftment}

To examine whether ABO group can influence PLT engraftment, we specifically examined PLT engraftment times by patient $\mathrm{ABO}$ type at all three CD34+ cell doses (Table 3; Fig. 2). There were no significant differences in either mean engraftment times (Table 3 ) or the probability of PLT engraftment (not shown), by ABO type at transplant doses of greater than $3 \times 10^{6}$ per $\mathrm{kg}$. At low CD34+ doses, however, there was a trend toward delayed engraftment in group O patients. Relative to group A and B patients, early PLT engraftment was delayed nearly 2 days, and late engraftment, 12 to 14 days ( $p<0.001$ ). Likewise, the probability of achieving late PLT engraftment was significantly 

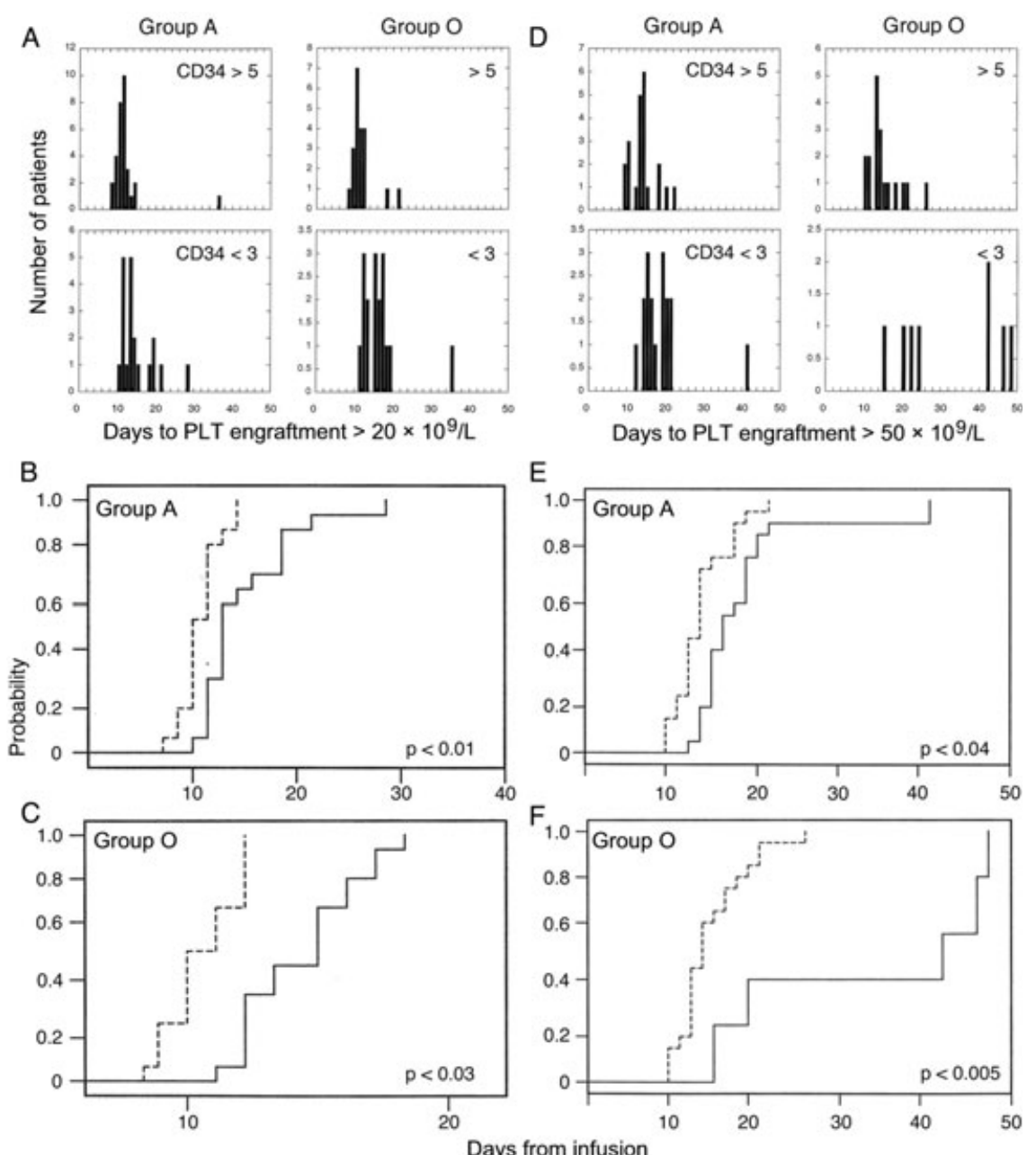

E
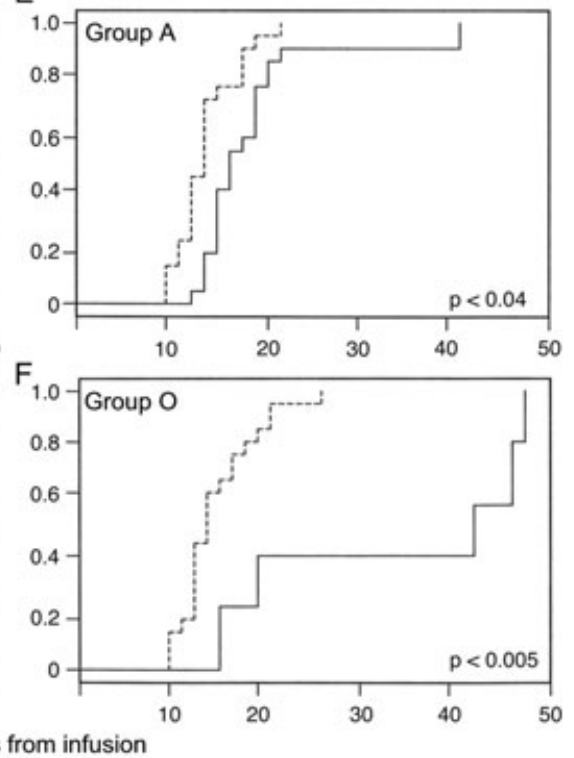

Fig. 2. Time to early (A) and late PLT engraftment (B) in group A and group $O$ patients at high $\left(\mathrm{CD34}>5\left[\times 10^{6}\right]\right)$ and low $\left(\mathrm{CD34}<3\left[\times 10^{6}\right]\right)$ CD34+ cell doses. Also shown are the Kaplan-Meier probabilities for early (B, C) and late PLT engraftment (E, F) by CD34+ cell dose in group $\mathrm{A}(\mathrm{B}, \mathrm{E})$ and group $\mathrm{O}(\mathrm{C}, \mathrm{F})$ patients, respectively. Engraftment times at high (- - ) and low (-) CD34+ transplant doses was compared by the log-rank test. engraftment among group $\mathrm{O}$ patients, we directly compared CD34+ dose and PLT engraftment for all patients transplanted at low CD34+ doses. There was no correlation between CD34+ yield and early $(r=0.18)$ and late $(r=0.10)$ PLT engraftment.

A detailed comparison of late PLT engraftment highlighted the differences between group $\mathrm{O}$ and nongroup $O$ patients. Whereas 75 percent of non-group $\mathrm{O}$ patients achieved a PLT count of greater than $50 \times 10^{9}$ per L by Day 20, only 13 percent of group $\mathrm{O}$ patients did. In fact, 50 percent of group $\mathrm{O}$ patients required more than 40 days for late engraftment. Despite this marked delay, there were no significant differences in either PLT or RBC transfusion support by ABO type (Table 4). This was not surprising given the lack of correlation between PLT recovery and PLT $(r=0.14)$ and RBC utilization $(\mathrm{r}=0.39)$ in individual patients (data not shown). ${ }^{27}$

After analysis of the data, it was clear that delayed recovery occurred in a subset of group $\mathrm{O}$ patients. We therefore performed a subanalysis of all patients transplanted at low $\mathrm{CD} 34+$ cell doses, regardless of ABO type, who required more than 35 days for to achieve a PLT count of greater than $50 \times 10^{9}$ per L. As before, there were no significant differences in sex $(57 \%$ male), age ( $51 \pm 13$ years; range, 2260 years), underlying diagnosis, WBC engraftment (11.3 \pm 0.5$)$, CD34+ cell dose (2.27 \pm 0.28$)$, and MNC dose (6.5 \pm 2.2 ; range, 4-9.9). Late PLT engraftment was preceded by delays in early PLT engraftment (20.2 days; range, 15-40 days) and was accompanied by increased PLT (40.8 \pm 17.4 ; range, 20-70) and RBC (6.8 \pm 2.7 ; range, 4-11) utilization. Increased PLT utilization was not due to PLT refractoriness: No patient transplanted at low CD34 doses had evidence of clinical refractoriness. Among patients requiring more than 35 days to reach late PLT engraftment, 70 percent were group $\mathrm{O}(\mathrm{p}<0.02)$.

\section{PLT recovery and CD34 mobilization}

Because of reports indicating that poor mobilization increases the probability for slow and/or poor PLT recovery after $\mathrm{PBPCT},{ }^{22}$ we performed an analysis comparing 
the number of PBPC collections per patient relative to late PLT engraftment at low CD34+ doses. On average, patients requiring more than 35 days for late PLT engraftment needed slightly more PBPC collections, with 70 percent of patients requiring at least six $\mathrm{PBPC}$ collections to achieve a CD34 cell dose of greater than $2 \times 10^{6}$ per $\mathrm{kg}(5.5 \pm 1.9$; range, 3-7). When we examined all patients transplanted at low CD34+ doses, however, we found no correlation between the number of PBPC collections and late PLT engraftment $(p>0.15)$.
We also examined six of seven patients with poor mobilization who required "remobilization" with GM-CSF and G-CSF or high dose G-CSF. Although these patients required between 8 and 10 leukapheresis procedures per patient, there was no significant delay in either early (range, 10-16 days) or late (range, 10-28 days) PLT engraftment. Likewise, there was no correlation between $\mathrm{ABO}$ type and poor mobilization in this group of patients (group $\mathrm{A}, \mathrm{n}=2$; group $\mathrm{B}, \mathrm{n}=1$; group $\mathrm{O}, \mathrm{n}=2$; $\operatorname{group} \mathrm{AB}$, $\mathrm{n}=1$ ). In summary, poor mobilization is not correlated with either delayed late PLT engraftment or group $\mathrm{O}$ phenotype.

\section{DISCUSSION}

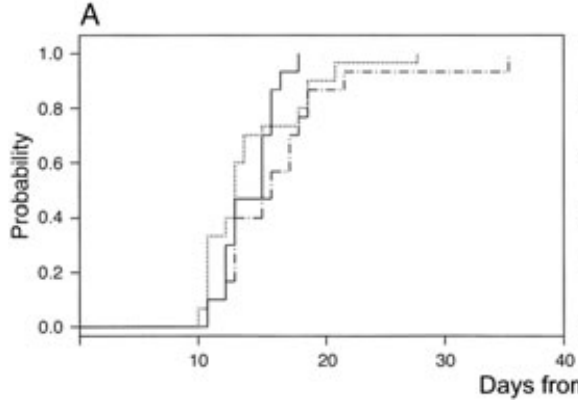

B

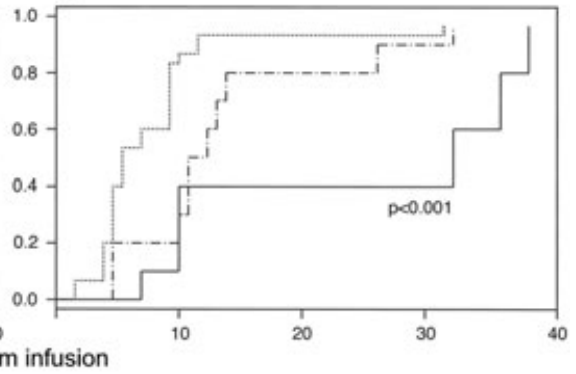

Fig. 3. Kaplan-Meier probability for early (A) and late (B) PLT engraftment in all group A $(\cdots)$, non-group $\mathrm{O}(-\cdot-)$, and group $\mathrm{O}(-)$ patients at low CD34 transplant doses. There was a significant delay in late PLT engraftment in group 0 patients $(p<0.001, \log$-rank test).
Advances in PBPC mobilization, collection, and transplant support, particularly the use of G-CSF and other growth factors, have markedly decreased the morbidity and mortality associated with PBPCT by decreasing the period of absolute neutropenia. ${ }^{22,27}$ As a consequence, the vast majority of patients achieve WBC engraftment within 2 weeks of transplant. $^{20-24}$ In contrast, many patients still experience delays in PLT

\begin{tabular}{|c|c|c|c|c|c|}
\hline & \multirow{2}{*}{$\begin{array}{c}\text { Group O } \\
\text { (mean } \pm \text { SD) }\end{array}$} & \multicolumn{2}{|c|}{ Group A } & \multicolumn{2}{|c|}{ Non-group $\mathrm{O}^{*}$} \\
\hline & & $\overline{M e a n} \pm$ SD & $\mathrm{P}$ value† & $\overline{M e a n} \pm$ SD & $\mathrm{P}$ value \\
\hline Number of patients & 18 & 28 & & 36 & \\
\hline Absolute neutrophil count $>500$ (days) & $11.9 \pm 1.1$ & $11.5 \pm 1.0$ & NS & $11.5 \pm 0.9$ & NS \\
\hline PLT count $>20 \times 10^{9} / \mathrm{L}$ (days) & $16.0 \pm 2.6$ & $14.5 \pm 4.3$ & NS & $14.6 \pm 4.2$ & NS \\
\hline PLT count $>50 \times 10^{9} / \mathrm{L}$ (days) $\ddagger$ & $32.4 \pm 13.3$ & $18.5 \pm 6.4$ & $<0.001$ & $19.6 \pm 7.9$ & $<0.001$ \\
\hline Percent engrafting $<20$ days $\S$ & 13 & 77 & $<0.005$ & 73.7 & $<0.005$ \\
\hline Percent engrafting $>40$ days $\S$ & 50 & 6 & $<0.01$ & 4.5 & $<0.005$ \\
\hline $\begin{array}{l}\text { Number of units of PLTs } \\
\text { transfused (range) }\end{array}$ & $\begin{array}{l}30.8 \pm 17.7 \\
(5-70)\end{array}$ & $\begin{array}{l}28 \pm 16.7 \\
(5-80)\end{array}$ & NS & $\begin{array}{l}27.2 \pm 14.0 \\
\quad(5-80)\end{array}$ & NS \\
\hline $\begin{array}{l}\text { Number of units of RBCs } \\
\text { transfused (range) }\end{array}$ & $\begin{array}{c}6.7 \pm 3.4 \\
(2-12)\end{array}$ & $\begin{array}{l}5.0 \pm 2.4 \\
(2-12)\end{array}$ & $<0.05$ & $\begin{array}{l}5.2 \pm 2.6 \\
(2-12)\end{array}$ & NS \\
\hline CD34 dose $\left(\times 10^{6} / \mathrm{kg}\right)$ & $2.41 \pm 0.31$ & $2.36 \pm 0.35$ & NS & $2.36 \pm 0.33$ & NS \\
\hline $\mathrm{MNCs} / \mathrm{kg}\left(\times 10^{8} / \mathrm{kg}\right)$ & $3.63 \pm 3.03$ & $4.02 \pm 3.05$ & NS & $3.78 \pm 3.38$ & NS \\
\hline $\begin{array}{l}\text { Number of PBPC procedures/ } \\
\text { patient (range) }\end{array}$ & $\begin{array}{c}4.3 \pm 3.1 \\
(1-8)\end{array}$ & $\begin{array}{c}4.1 \pm 2.3 \\
(1-8)\end{array}$ & NS & $\begin{array}{c}4.0 \pm 2.4 \\
(1-10)\end{array}$ & NS \\
\hline $\begin{array}{l}\text { Patient age, years } \\
\text { (range) }\end{array}$ & $\begin{array}{l}49 \pm 14.5 \\
(22-62)\end{array}$ & $\begin{array}{l}44 \pm 15 \\
(21-71)\end{array}$ & NS & $\begin{array}{l}46 \pm 15.3 \\
(21-71)\end{array}$ & NS \\
\hline \multicolumn{6}{|l|}{$\operatorname{Sex}(\%)$} \\
\hline Male & 61 & 70 & NS & 66 & NS \\
\hline Female & 39 & 30 & NS & 33 & NS \\
\hline \multicolumn{6}{|l|}{ Primary diagnosis (\%) } \\
\hline Hodgkin's lymphoma & 33 & 41 & NS & 33 & NS \\
\hline Non-Hodgkin's lymphoma & 33 & 37 & NS & 42 & NS \\
\hline Multiple myeloma & 33 & 22 & NS & 22 & NS \\
\hline \multicolumn{6}{|c|}{$\begin{array}{l}\text { All non-group O patients (group A, B and AB). } \\
\text { † T test; NS = not significant }(\mathrm{p}>0.05) \text {. } \\
\text { ‡ Difference between group O, group A, and all non-group O also significant by multivariate analysis }(\mathrm{p}=0.0013) \text {. } \\
\text { \& Chi-square test. } \\
\text { ॥ Whole blood-derived PLT concentrates ( } 99.3 \% \text { of all PLTs). Two patients each received a single unit of apheresis PLT concentrates }(0.7 \% \\
\text { total) based on available inventory. Neither patient had evidence of clinical PLT refractoriness. }\end{array}$} \\
\hline
\end{tabular}


engraftment with the attendant risks of bleeding, alloimmunization, multiorgan failure, and increased mortality. ${ }^{28-30}$ Although many clinical factors are reportedly associated with delays in PLT engraftment, ${ }^{28}$ the single strongest predictor is the CD34+ cell dose. Several studies have verified a significant inverse relationship between CD34+ cell dose and PLT engraftment kinetics, with an estimated threshold minimum of at least $5 \times 10^{6} \mathrm{CD} 34+$ cells per $\mathrm{kg}$ of body weight for rapid PLT recovery. ${ }^{20-24}$ PBPCT at low CD34+ doses, however, does not guarantee slow PLT engraftment, suggesting the involvement of other factors. ${ }^{28,31}$

We also found a strong correlation between CD34+ cell dose and the rate of PLT recovery. Although WBC engraftment was essentially equivalent at all CD34+ doses of greater than $2 \times 10^{6}$ per $\mathrm{kg}$, there was a significant doseresponse relationship between CD34 dose and early and late PLT engraftment. As reported, ${ }^{20-22}$ rapid PLT engraftment was observed at $5 \times 10^{6} \mathrm{CD} 34+$ cells per $\mathrm{kg}$ with no significant shortening at higher CD34 doses (data not shown). Interestingly, we found nearly equivalent mean engraftment times at intermediate CD34 doses $\left(>3 \times 10^{6}\right)$. In contrast, autologous PBPCT at CD34 doses $<3 \times 10^{6}$ CD34+ cells per kg of body weight were associated with significant delays in PLT engraftment. Our findings are consistent with other studies, but suggest that a threshold yield of $3 \times 10^{6} \mathrm{CD} 34+$ cells per kg is sufficient for rapid WBC and early PLT engraftment.

The relationship between CD34+ PBPC dose and PLT engraftment kinetics is believed to reflect the dose of committed megakaryocyte progenitors transplanted. ${ }^{32-35}$ Mobilized CD34+ PBPCs are a heterogeneous population consisting of uncommitted pluripotent progenitor cells and primitive lineage-committed progenitors, including early megakaryocyte progenitors, which comprise 6 to 8 percent of all CD34+ cells (range, $1 \%-28 \%$ ). ${ }^{34-36}$ Several clinical investigators have shown that the dose of these early committed megakaryocyte progenitors, as determined by CD34+CD41+ cells, is inversely related to the rate of PLT engraftment in vivo ( $r=-0.60$ to 0.81$)^{32,33,35}$ Optimal engraftment is observed at CD34+CD41+ doses of greater than $1 \times 10^{5}$ per $\mathrm{kg}$ of body weight, which is roughly equivalent to a total CD34+ PBPC dose of at least $5 \times 10^{6}$ per kg of body weight. ${ }^{21,32}$ Interestingly, transplants with highly purified, primitive CD34+ cells, which lack these early megakaryocyte progenitors, are associated with profoundly delayed PLT engraftment, decreased marrow megakaryocytes, and altered megakaryocytopoiesis. ${ }^{37}$

We also examined the effect of recipient $\mathrm{ABO}$ type and engraftment. As noted earlier, an $\mathrm{H}$-active antigen is strongly and developmentally expressed on progenitor cells and immature megakaryocytes, ${ }^{13-15}$ with expression decreasing with increasing ploidy and megakaryocyte maturation. As a consequence, we hypothesized that patient $\mathrm{ABO}$ type might influence the rate of PLT recovery after PBPCT. Contrary to our original hypothesis, there was a trend toward delayed engraftment at low CD34+ cell doses in group $\mathrm{O}$ patients. This delay was independent of other potential confounding factors and was specific for CD34+ doses between $2 \times 10^{6}$ and $3 \times 10^{6}$ per $\mathrm{kg}$ of body weight. To our knowledge, this is the first report suggesting a relationship between PLT engraftment kinetics and ABO type.

How ABO group could influence megakaryocyte development and PLT recovery is unknown. Multiple studies have shown that the regulation of human megakaryocytopoiesis is a complex process that occurs through a synergistic interaction between megakaryocytic precursors, marrow stromal cells, endothelial cells, and the ECM. ${ }^{36,38,39}$ Megakaryocyte adhesion to stromal fibroblasts and ECM proteins, such as fibronectin, promotes the survival and expansion of megakaryocytic precursors in vivo and ex vivo. ${ }^{16-18,40}$ Interestingly, there is evidence that the adhesion of megakaryocytes to marrow fibroblasts is influenced by fucosylation and may, in fact, be fucosedependent. Schmitz and colleagues ${ }^{16}$ were able to inhibit megakaryocyte adhesion to stromal fibroblasts with fucosylated bovine serum albumin, fucose-specific lectins (Ulex europeaus lectin-1 and Anguilla anguilla), and soluble $\mathrm{H}$-antigen ( $\alpha$ Fuc-1,2Gal $\beta$-HAS) ${ }^{16}$ Their studies concluded that megakaryocytes express a fucosylated, possibly $\mathrm{H}$-active ligand that acts as a counterreceptor for a fucose-specific lectin on marrow stromal fibroblasts.

Several glycoproteins critical to megakaryocyte development and adhesion are known to express $\mathrm{ABO}$-antigens, including GPIIb/IIIa (CD41), GPIba (CD42), and PECAM (CD31). ${ }^{41,42}$ An early marker of megakaryocytic and erythroid differentiation, GPIIb/IIIa binds the ECM and marrow fibroblasts ${ }^{43}$ and is required for erythroid, megakaryocyte, and pleuripotent progenitor maintenance. ${ }^{38}$ GPIba and PECAM are later megakaryocytic markers and may contribute to growth arrest and proplatelet formation, respectively. ${ }^{38,44,45} \mathrm{ABO}$ antigens are also expressed by $\alpha 4 \beta 1$ and $\alpha 5 \beta 1$ integrins, where they are known to directly influence integrin function. In epithelial tumors, loss of A/B antigens, with a concomitant increase in $\mathrm{H}$ and $\mathrm{Le}^{\mathrm{Y}}$, is associated with increased fibronectin binding, cell adhesion, cell motility, and resistance to apoptosis. ${ }^{46-48}$ In marrow, integrins mediate CD34+ PBPCs and megakaryocyte adhesion to ECM and stromal fibroblasts, ${ }^{40,45,49}$ inhibiting apoptosis, ${ }^{50}$ while promoting fibroblast growth, megakaryocyte differentiation, and proplatelet formation. . $^{18,39,45}$

Finally, $\mathrm{ABO}$ might influence the binding and cellular response to required growth factors. The best known example is the epidermal growth factor receptor, a glycoprotein important in cell growth regulation and tumorigenesis. ${ }^{51,52}$ On RBCs, there is a strong correlation between $\mathrm{ABO}$ type and high-affinity binding. ${ }^{53}$ In epithelial and PBPCs, $\mathrm{ABH}$ influences epidermal growth factor 
and epidermal growth factor receptor expression, ${ }^{54}$ autophosphorylation, and protein kinase activity. ${ }^{55,56}$ Although it is not clear whether epidermal growth factor receptor contributes to megakaryocytic differentiation, ${ }^{57}$ $\mathrm{ABO}$ antigens may be expressed on $\mathrm{N}$-glycans of other growth factors necessary for fibroblast and megakaryocyte growth..$^{58,59}$

Based on our findings and those of others, we hypothesize that $\mathrm{H}$ is a developmentally regulated antigen that may play a critical role during megakaryocytopoiesis. Specifically, fucose-mediated adhesion to marrow fibroblasts and the ECM, possibly via $\mathrm{H} / \mathrm{Le}^{\mathrm{Y}}$ on integrins, may promote the expansion and/or maintenance of committed, self-renewing megakaryocytic progenitors while inhibiting terminal differentiation. ${ }^{16,17}$ In group $\mathrm{O}$ individuals, fucose-mediated adhesion and signaling may be prolonged relative to group A and B patients, leading to delayed megakaryocyte maturation and PLT recovery. This delay may be relatively subtle and only observed at limiting numbers of megakaryocyte progenitors.

In summary, we have confirmed the inverse correlation between CD34+ cell dose and PLT engraftment kinetics. In addition, we report that $\mathrm{ABO}$ type may influence PLT engraftment at low CD34+ PBPC doses. Specifically, there is an increased probability of delayed engraftment among group $\mathrm{O}$ patients at CD34+ doses of $2 \times 10^{6}$ to $3 \times 10^{6}$ per kg of body weight. With the advent of ex vivo culturing techniques, it may now be possible to delineate the regulation and role of $\mathrm{ABO}$ antigen expression in megakaryocytopoiesis. In contrast, humanized murine PBPCT models, utilizing SCID mice transplanted with human PBPCs, ${ }^{60}$ may not be applicable owing to intrinsic differences in $\mathrm{ABO}$ and glycosyltransferase expression between mice and humans. ${ }^{61}$

\section{REFERENCES}

1. Chan YH, Watt SM. Adhesion receptors on haematopoietic progenitor cells. Br J Haematol 2001;112:541-57.

2. Haltiwanger RS. Regulation of signal transduction pathways in development by glycosylation. Curr Opin Struct Biol 2002;12:593-8.

3. Gonzalez-Amaro R, Sanchez-Madrid F. Cell adhesion molecules: selectins and integrins. Crit Rev Immunol 1999;19:389-429.

4. Cooling L, Zhang DS, Koerner TA. Lewis X and sialyl Lewis X glycosphingolipids. Trends Glycoscience Glycotech 1997;9: 191-209.

5. Mazo IB, von Adrian UH. Adhesion and homing of bloodborne cells in bone marrow microvessels. J Leukocyte Biol 1999;66:25-32.

6. Carlesso N, Aster JC, Sklar J, Scadden DT. Notch1-induced delay of human hematopoietic progenitor cell differentiation is associated with altered cell cycle kinetics. Blood 1999; 93:838-48.
7. Varnum-Finney B, Xu L, Brashem-Stein C, et al. Pluripotent, cytokine-dependent, hematopoietic stem cells are immortalized by constitutive Notch1 signaling. Nat Med 2000;6:1278-81.

8. Allman D, Aster JC, Pear WS. Notch signaling in hematopoiesis and early lymphocyte development. Immunol Rev 2002;187:75-86.

9. Milner LA, Bigas A, Kopan R, et al. Inhibition of granulocytic differentiation by mNotch1. Proc Natl Acad Sci U S A 1996;93:13014-9.

10. Moloney DJ, Panin VM, Johnston SH, et al. Fringe is a glycosyltransferase that modifies Notch. Nature 2000; 406:369-75.

11. Okajima T, Xu A, Irvine KD. Modulation of notch-ligand binding by protein O-fucosyltransferase 1 and fringe. J Biol Chem 2003;278:42340-5.

12. Zhou L, Myers J, Petryniak B, et al. Delta-like 1-induced Notch activation in hematopoietic stem cell: a process disturbed by absence of fucosylation. Transfusion 2003;43S:12A.

13. Cao Y, Merling A, Karsten U, Schwartz-Albiez R. The fucosylated histo-blood group antigens $\mathrm{H}$ (type 2 blood group O, CD173) and Lewis Y (CD174) are expressed on CD34+ hematopoietic progenitors but absent on mature lymphocytes. Glycobiology 2001;11:677-83.

14. Hosoi E, Hirose M, Hamano S. Expression levels of H-type $\alpha(1,2)$-fucosyltransferase gene and histo-blood group ABO gene corresponding to hematopoietic cell differentiation. Transfusion 2003;43:65-71.

15. Okumura M, Morishima Y, Michinori O, et al. Expression of H-related antigen on human megakaryocytes and megakaryocytic leukemic cells. Int J Hematol 1991;54:151-8.

16. Schmitz B, Thiele J, Otto F, et al. Interactions between endogenous lectins and fucosylated oligosaccharides in megakaryocyte-dependent fibroblast growth of the normal bone marrow. Leukemia 1996;10:1604-14.

17. Zweegman S, Veenhof MA, Huijgens PC, Schuurhuis GJ, Drager AM. Regulation of megakaryocytopoiesis in an in vitro stroma model: preferential adhesion of megakaryocytic progenitors and subsequent inhibition of maturation. Exp Hematol 2000;28:401-10.

18. Han P, Guo XH, Story CJ. Enhanced expansion and maturation of megakaryocytic progenitors by fibronectin. Cytotherapy 2002;4:277-83.

19. Sutherland DR, Anderson L, Keeney M, et al. The ISHAGE guidelines for CD34+ cell determination by flow cytometry. International society for hematotherapy and graft engineering. J Hematother 1996;5:213-26.

20. Diaz MA, Vicent MG, Garcia-Sanchez F, Vicario JL, Madero L. Long-term hematopoietic engraftment after autologous peripheral blood progenitor cell transplantation in pediatric patients: effect of the CD34+ cell dose. Vox Sang 2000;79:14550 .

21. Kiss JE, Rybka WB, Winkelstein A, et al. Relationship of CD34+ cell dose to early and late hematopoiesis following 
autologous peripheral blood stem cell transplantation. Bone Marrow Transplant 1997;19:303-10.

22. Weaver $\mathrm{CH}$, Hazelton B, Birch R, et al. An analysis of engraftment kinetics as a function of the CD34 content of peripheral blood progenitor cell collections in 692 patients after the administration of myeloablative chemotherapy. Blood 1995;86:3961-9.

23. Feugier P, Bensoussan D, Girard F, et al. Hematologic recovery after autologous $\mathrm{PBPC}$ transplantation: importance of the number of postthaw CD34+ cells. Transfusion 2003;43:878-84.

24. Beguin Y, Baudoux E, Sautois B, et al. Hematopoietic recovery in cancer patients after transplantation of autologous blood CD34+ cells or unmanipulated peripheral blood stem and progenitor cells. Transfusion 1998;83:199208.

25. Kaplan EL, Meier P. Nonparametric estimation from incomplete observations. J Am Stat Assoc 1958;53:457.

26. Smith RJ, Sweetenham JW. A mononuclear cell dose of $3 \times$ $10^{8} / \mathrm{kg}$ predicts early multilineage recovery in patients with malignant lymphoma treated with carmustine, etoposide, Ara-C and melphalan (BEAM) and peripheral blood progenitor cell transplantation. Exp Hematol 1995;23: 1581-8.

27. Menendez P, Caballero MD, Prosper F, et al. The composition of leukapheresis products impacts on the hematopoietic recovery after autologous transplantation independently of the mobilization regimen. Transfusion 2002;42:1159-72.

28. Nash RA, Gooley T, Davis C, Appelbaum FR. The problem of thrombocytopenia after hematopoietic stem cell transplantation. Oncologist 1996;1:371-80.

29. Benjamin RJ, Antin JH. ABO-incompatible bone marrow transplantation: the transfusion of incompatible plasma may exacerbate regiment-related toxicity. Transfusion 1999;39:1273-4.

30. Gordon B, Tarantolo S, Ruby E, et al. Increased platelet transfusion requirement is associated with multiple organ dysfunctions in patients undergoing hematopoietic stem cell transplantation. Bone Marrow Transplant 1998;22:9991003.

31. Robinson SN, Freedman AS, Neuberg DS, Nadler LM, Mauch $\mathrm{PM}$. Loss of marrow reserve from dose-intensified chemotherapy results in impaired hematopoietic reconstitution after autologous transplantation: CD34(+), CD34(+)38(-), and week-6 CAFC assays predict poor engraftment. Exp Hematol 2000;28:1325-33.

32. Kanamaru S, Kawano Y, Watanabe T, et al. Low numbers of megakaryocyte progenitors in grafts of cord blood cells may result in delayed platelet recovery after cord blood cell transplant. Stem Cells 2000;18:190-5.

33. Feng R, Shimazaki C, Inaba T, et al. CD34+/CD41a+ cells best predict platelet recovery after autologous peripheral blood stem cell transplantation. Bone Marrow Transplant 1998; 21:1217-22.
34. Dercksen MW, Rodenhuis S, Dirkson MK, et al. Subsets of CD34+ cells and rapid hematopoietic recovery after peripheral-blood stem-cell transplantation. J Clin Oncol 1995;13:1922-32.

35. Begemann PG, Hassan HT, Kroger N, et al. Correlation of time to platelet engraftment with amount of transplanted CD34+CD41+ cells after allogeneic bone marrow transplantation. J Hematother Stem Cell Res 2002;11:321-6.

36. Hoffman R, Bruno E. Human megakaryocyte progenitor cells. Semin Hematol 1998;35:183-91.

37. Bradford G, Williams N, Barber L, Bertoncello I. Temporal thrombocytopenia after engraftment with defined stem cells with long-term marrow reconstituting activity. Exp Hematol 1993;21:1615-20.

38. Mossuz P, Schweitzer A, Molla A, Berthier R. Expression and function of receptors for extracellular matrix molecules in the differentiation of human megakaryocytes in vitro. Br J Haematol 1997;98:819-27.

39. Rafii S, Mohle R, Shapiro F, Frey BM, Moore MA. Regulation of hematopoiesis by microvascular endothelium. Leuk Lymphoma 1997;27:375-86.

40. Scjick PK, Wojenski CM, He X, et al. Integrins involved in the adhesion of megakaryocytes to fibronectin and fibrinogen. Blood 1998;92:2650-6.

41. Cooling L. ABO and human blood platelets. ADVANCE for Laboratory Administrators 2004;13:72-8.

42. Santoso S, Kiefel V, Mueller-Eckhardt C. Blood group A and B determinants are expressed on platelet glycoproteins IIa, IIIa, and Ib. Thromb Haemostasis 1991;65:196-201.

43. Wickenhauser C, Schmitz A, Baldus SE, et al. Selectins (CD62L, CD62P) and megakaryocytic glycoproteins (CD41a, CD42b) mediate megakaryocyte-fibroblast interactions in human bone marrow. Leukemia Res 2000;24:1013-21.

44. Feng S, Christodoulides N, Kroll MH. The glycoprotein Ib/IX complex regulates cell proliferation. Blood 1999;93: 4256-63.

45. Molla A, Mossuz P, Berthier R. Extracellular matrix receptors and the differentiation of human megakaryocytes in vitro. Leuk Lymphoma 1999;33:15-23.

46. Ichikawa D, Handa K, Withers DA, Hakomori SI. Histo-blood group A/B versus $\mathrm{H}$ status of human carcinoma cells as correlated with haptotactic cell motility: approach with A and B gene transfection. Cancer Res 1997;57:3092-6.

47. Ichikawa D, Handa K, Hakomori SI. Histo-blood group A/B antigen deletion/reduction vs. continuous expression in human tumor cells as correlated with their malignancy. Int J Cancer 1998;76:284-9.

48. Groupille C, Marionneau S, Bureau V, et al. $\alpha 1,2-$ Fucosyltransferase increases resistance to apoptosis of rat colon carcinoma cells. Glycobiology 2000;10:375-82.

49. Carion A, Domenech J, Herault O, et al. Decreased stroma adhesion capacity of CD34+ progenitor cells from mobilized peripheral blood is not lineage- or stage-specific and is associated with low $\beta 1$ and $\beta 2$ integrin expression. J Hematother Stem Cell Res 2002;11:491-500. 
50. Bendall LJ, Daniel A, Kortlepel K, Gottlieb DJ. Bone marrow adherent layers inhibit apoptosis of acute myeloid leukemia cells. Exp Hematol 1994;22:1252-60.

51. Cummings RD, Soderquist AM, Carpenter G. The oligosaccharide moities of the epidermal growth factor receptor in A-431 cells: presence of complex-type N-linked chains that contain terminal $N$-acetylgalactosamine residues. J Biol Chem 1985;260:11944-52.

52. Le Pendu J, Fredman P, Richter ND, et al. Monoclonal antibody 101 that precipitates the glycoprotein receptor for epidermal growth factor is directed against the $\mathrm{Y}$ antigen, not the $\mathrm{H}$ type 1 antigen. Carbohydrate Res 1985;141: 347-9.

53. Engelemann B, Schumacher U, Haen E. Epidermal growth factor binding sites on human erythrocytes in donors with different ABO blood groups. Am J Hematol 1992;39: 239-41.

54. Kong Y, Ge CH, Li H, Zhu ZM. Effects of Lewis Y oligosaccharide on secretion and gene expression of EGF and EGF-R in mouse embryos. Acta Biochim Biophys Sinica 2002;34:373-7.

55. Defize LH, Arndt-Jovin DJ, Jovin TM, et al. A431 cell variants lacking the blood group A antigen display increased high affinity epidermal growth factor-receptor number, protein- tyrosine kinase activity, and receptor turnover. J Cell Biol 1988;107:939-49.

56. Klinger M, Farhan H, Just H, et al. Antibodies directed against Lewis- $\mathrm{Y}$ antigen inhibit signaling of Lewis- $\mathrm{Y}$ modified ErbB receptors. Cancer Res 2004;64:1087-93.

57. Kimura A, Katoh O, Kuramoto A. Effects of platelet-derived growth factor, epidermal growth factor and transforming growth factor- $\beta$ on the growth of human marrow fibroblasts. Fr J Haematol 1988;69:9-12.

58. Feige JJ, Baird A. Glycosylation of the basic fibroblast growth factor receptor: the contribution of carbohydrate to receptor function. J Biol Chem 1988;263:14023-9.

59. Bruno E, Cooper RJ, Wilson EL, Gabrilove JL, Hoffman R. Basic fibroblast growth factor promotes the proliferation of human megakaryocyte progenitor cells. Blood 1993;82:4305.

60. Angelopoulou MK, Rinder H, Wang C, et al. A preclinical xenotransplantation animal model to assess human hematopoietic stem cell engraftment. Transfusion 2004;44:555-66.

61. Oriol R. Tissular expression of $\mathrm{ABH}$ and Lewis antigens in humans and animals: expected value of different animal models in the study of ABO-incompatible organ transplants. Transplant Proc 1987;19:4416-20. 